\title{
Changes in Ovarian Function after Radioactive lodine among Patients with Differentiated Thyroid Carcinoma at St. Luke's Medical Center, Philippines
}

\author{
Michael D. Rosario ${ }^{1}$, Gabriel V. Jasul, Jr. ${ }^{2}$ \\ ${ }^{1}$ Section of Endocrinology, Diabetes \& Metabolism, St. Luke's Medical Center, Philippines \\ ${ }^{2}$ Section of Endocrinology, Diabetes \& Metabolism, St. Luke's Medical Center, Philippines \\ Section of Endocrinology, University of the Philippines-Philippine General Hospital
}

\begin{abstract}
Objective. To determine the prevalence of menstrual and reproductive dysfunction among subjects who have undergone radioiodine treatment for thyroid carcinoma.
\end{abstract}

Methodology. This study enrolled adult women with Differentiated Thyroid Carcinoma who received the treatment at age 40 years and below. Data was processed using SAS program and evaluated using Fischer's test and Wilcoxon test.

Results. The study enrolled 46 women. Three reported cycle irregularities, 4 reported changes in amount of bleeding and 1 had amenorrhea. The prevalence rate of menstrual abnormalities was $15.2 \%$. These women received a significantly higher dose of radioactive iodine (RAI) (120 vs. $110 \mathrm{mCi}, \mathrm{p}=0.0064)$.

Eleven women tried to conceive and there were 5 births to 5 different subjects after radiation. There were no congenital anomalies and 1 miscarriage. Four women were menopausal with an average age of 44.4 years old.

Conclusion. This study showed that the prevalence of menstrual disturbances after high dose radioactive iodine treatment among thyroid cancer patients is $15.2 \%$. The affected group received a significantly higher dose of radioactive iodine compared to the unaffected group.

Keywords: Ovarian Dysfunction, Thyroid Cancer, Radioactive lodine

\section{Introduction}

Thyroid cancer is one of the most common cancers worldwide. Treatment of differentiated thyroid carcinoma is multifaceted and one integral part of management is radioactive iodine given after surgery to ablate any remaining normal thyroid tissue as well as any pathologic remnants. With the increasing use of radioactive iodine in the younger population, there are concerns about possible long term effects, specifically on menstrual and reproductive function. During ablative therapy, the gonads are exposed to radiation via various sources such as the bowels and the urinary bladder. Exposure is further augmented by the decreased clearance of radioiodine due to hypothyroidism prior to ablation.

This study aims to gather data on the ovarian function of women who have undergone radioiodine treatment for thyroid carcinoma. Specifically, it reviewed menstrual abnormalities occurring after radioactive ablation. The post ablation reproductive history was reviewed and the timing of menopausal onset was also determined whenever applicable.
This is the first local study to gather data on reproductive function among female thyroid cancer patients who have received ablative doses of radioiodine. The results could assist clinicians in assessing, monitoring and possibly prognosticating ovarian dysfunction for future patients.

\section{Materials and Methods}

This is a retrospective cohort study among Filipino adult women diagnosed with Differentiated Thyroid Carcinoma who have undergone thyroid surgery and radioactive iodine (RAI) ablation and are on thyroid hormone therapy. Subjects should have received the first dose of radioactive iodine ablation at age 40 years and below, with an interval of at least 1 year from time of ablation to time of consult. Sample size was computed used EpiInfo 6. The calculated sample size for a 95\% confidence interval with a margin of error of $7 \%$, was 46 subjects. This was based on a $17 \%$ prevalence cited in one study. ${ }^{1}$

Potential subjects were screened at the General Endocrine Clinic of the Social Services Out-Patient Section of the St. Luke's Medical Center. All women who qualified based on the selection criteria mentioned previously were

Corresponding author: Michael D. Rosario, MD

Mailing address: 73 Mapagkawanggawa St., Teachers Village, Quezon City, 1101 Telephone number: 921-6295

Email address: Mickeyrosario@ymail.com 
included in the study. During the single study visit, the subjects were interviewed by a single investigator and information was collected using a data collection form.

The first part of the interview focused on the thyroid problem. Data gathered included details of the surgery such as place, date, number and types of procedures performed and the histopathologic diagnosis. Questions on the radioactive iodine history included date and place of administration, number of RAI ablations performed and total dose received.

The individual menstrual cycle history before surgery, after surgery and after each episode of radioactive iodine administration was then reviewed. The subject was asked for any changes in cycle regularity and amount of menstrual flow and for any episodes of amenorrhea especially during the first 12 months after radioactive iodine ablation. A change in the duration between cycles of more than 2 days was considered as irregular. A difference in the number of napkins used or the duration of the menstrual period from the patient's usual pattern was considered as a change in menstrual flow. We also inquired if the patient sought any medical consult for such menstrual changes.

The reproductive history before surgery and after radioactive iodine was also investigated. This included the number of live births, stillbirths, miscarriages and any work up for infertility. The presence of congenital anomalies was also determined. The patients were also screened if they reached menopause at the time of the interview, defined as the absence of menses for 12 months after the last menses. The age of onset and cause of menopause was also determined.

Data was encoded in Microsoft Excel ver. 2003. Data processing and analysis was performed using SAS program. Data was evaluated using Fischer's test and Wilcoxon test.

\section{Results}

The study included 46 women (see Table 1 ). The average age at the time of first RAI administration was 32.9 years with a range of 19-40 years. There were 36 cases of Papillary Carcinoma, 9 cases of Follicular Cancer and 1 mixed case. Majority underwent one operation only, while 15 subjects underwent 2 surgeries. The average interval between surgery and radioactive iodine was 8 months.

Thirty seven of the women received only 1 dose of radioactive iodine at the time of interview with a mean activity of $113 \mathrm{mCi}$. The remaining nine women received a second dose and they received a mean cumulative activity of $284 \mathrm{mCi}$. None of the women received more than 2 doses.
Table 1. Patient characteristics

Number of subjects

Age Range and Average at the time of

First Radioactive lodine

Diagnosis

\begin{tabular}{|c|c|c|}
\hline & $\begin{array}{r}\text { Papillary Cancer } \\
\text { Follicular Cancer } \\
\text { Mixed }\end{array}$ & $\begin{array}{l}36 \\
9 \\
1\end{array}$ \\
\hline \multicolumn{3}{|c|}{ Number of surgeries } \\
\hline & 1 & 31 \\
\hline & 2 & 15 \\
\hline \multirow{3}{*}{\multicolumn{2}{|c|}{$\begin{array}{l}\text { Mean Interval and Range between } \\
\text { Surgery and First RAI (in months) } \\
\text { Number of RAI sessions }\end{array}$}} & 8.04 months \\
\hline & & (range $=2-91$ months) \\
\hline & & \\
\hline & 1 & 37 \\
\hline & 2 & 9 \\
\hline & 3 & 0 \\
\hline \multicolumn{3}{|c|}{ Mean total RAI dose received (in $\mathrm{mCi}$ ) } \\
\hline & Single session & $113.2 \mathrm{mCi}$ \\
\hline & 2 sessions & $284.4 \mathrm{mCi}$ \\
\hline
\end{tabular}

A total of 7 women reported menstrual changes after radioactive iodine (see Table 2). Three women reported that their cycle became irregular after treatment. Two women reported an increase in the amount, while two cases reported a decrease in amount. There was 1 case of amenorrhea which lasted for 3 months. These changes persisted up to the time of the interview for two cases. The remaining women's menstrual irregularities spontaneously resolved. All these changes were noted after the first dose of radioactive iodine. No such menstrual changes were elicited among patients who underwent a second course of treatment. All changes were noted within 6 months, with 6 of the women experiencing change immediately post RAI and one experiencing it 5 months later.

\begin{tabular}{lc} 
Table 2. Menstrual changes reported after radioactive \\
iodine & Number of events \\
\hline & 3 \\
\hline Cycle changes & 4 \\
Changes in amount & 1 \\
Episodes of amenorrhea & 8 \\
Total number of events &
\end{tabular}

The group who experienced menstrual cycle changes received a significantly higher activity of radioactive iodine $(120$ vs $110 \mathrm{mci}, \mathrm{p}$ value $=0.0064)$. These women were also older than the unaffected group but this was not significant (35.9 years vs 32.49 years, $p$ value $=0.3187$ ).

\begin{tabular}{|c|c|c|c|}
\hline & $\begin{array}{l}\text { With Menstrual } \\
\text { Cycle Changes }\end{array}$ & $\begin{array}{l}\text { Without Menstrual } \\
\text { Cycle Changes }\end{array}$ & $\begin{array}{c}P \\
\text { value }\end{array}$ \\
\hline Number of subjects & 7 & 39 & \\
\hline Age (in years) & $35.29 \pm 3.55$ & $32.49 \pm 5.74$ & $\begin{array}{c}0.318 \\
7\end{array}$ \\
\hline $\begin{array}{l}\text { Mean dose of RAI } \\
\text { when the abnormality } \\
\text { appeared (in mCi) }\end{array}$ & $\begin{array}{c}121.43 \pm \\
26.72\end{array}$ & $111.79 \pm 28.18$ & $\begin{array}{c}0.006 \\
4\end{array}$ \\
\hline $\begin{array}{l}\text { Mean duration from } \\
\text { surgery to RAI } \\
\text { (in months) }\end{array}$ & $16.86 \pm 32.84$ & $6.46 \pm 8.86$ & $\begin{array}{c}0.744 \\
0\end{array}$ \\
\hline
\end{tabular}

\section{Reproductive function}

After ablative therapy, 11 women tried to conceive (see Table 4). Overall, there were 5 births recorded after 
radiation treatment to 5 different subjects. There were no congenital anomalies recorded. These 5 women had an average age of 28.4 years old at the time of RAI ablation. They received a mean activity of $150 \mathrm{mCi}$ prior to the first post-treatment pregnancy, with one subject becoming pregnant after receiving a cumulative activity of $250 \mathrm{mCi}$. The shortest interval between RAI and pregnancy was 2 months. The longest interval was 12 years, although this patient married 10 years after treatment.

\begin{tabular}{|c|c|c|}
\hline & $\begin{array}{l}\text { Subjects with } \\
\text { pregnancies } \\
\text { occurring after } \\
\text { radioactive iodine }\end{array}$ & $\begin{array}{l}\text { Subjects without } \\
\text { pregnancies } \\
\text { occurring after } \\
\text { radioactive iodine }\end{array}$ \\
\hline Number of subjects & 5 & 6 \\
\hline $\begin{array}{l}\text { Mean age of first } \\
\text { Radioactive iodine }\end{array}$ & 28.4 years old & 35.2 years old \\
\hline $\begin{array}{l}\text { Mean cumulative dose } \\
\text { of radioactive iodine }\end{array}$ & $150 \mathrm{mCi}$ & $108 \mathrm{mCi}$ \\
\hline $\begin{array}{l}\text { Number of live births } \\
\text { after RAI }\end{array}$ & 5 & \\
\hline $\begin{array}{l}\text { Number of } \\
\text { miscarriages after RAI }\end{array}$ & 1 & \\
\hline $\begin{array}{l}\text { Number of congenital } \\
\text { anomalies after RAl }\end{array}$ & 0 & \\
\hline
\end{tabular}

The remaining 6 women were unable to conceive at the time of the study. They received radioactive iodine at an average age of 35.2 years and the average activity was 108 $\mathrm{mCi}$. One woman had no prior pregnancies prior to radioactive iodine. One woman had been trying since 1995. Two of the women had infrequent sexual contact with their partner due to the nature of their partner's work.

There was only 1 miscarriage after RAI, but this occurred in a patient who was 40 years old. Prior to this, the subject had a successful pregnancy occurring post ablation. There are no reports of congenital anomalies.

\section{Menopause}

Four women were menopausal at the time of the study. Their average age was 44.4 , with a range of 41 to 47 years old. The average age that they received their first RAI ablation was 34 years old with a range of 26 to 39 years. Two women received 2 doses of RAI and their cumulative activities were 300 and $325 \mathrm{mCi}$. The mean interval between the first RAI and onset of menopause was 10.5 years

\section{Discussion}

This study showed that $7(15 \%)$ of the 46 women interviewed, reported menstrual changes within the first 12 months after RAI ablation. Other studies have shown similar findings. In the study conducted by Vini ${ }^{1}$ among 409 women with a mean age of 31 years, 12\% developed new menstrual irregularities which were transient in nature. In a study done by Sioka ${ }^{2}, 17.8 \%$ of 45 women with previously normal menstrual cycles experienced changes after radioactive iodine.

Age at the time of radioactive iodine has been suggested as a risk factor. This study showed that the group with menstrual changes was older (35.3 years old vs. 32.5 years old) although it did not reach statistical significance. The study of Sioka showed a non-significant trend with increasing age and increasing susceptibility to menstrual disturbance after radiation. Vini suggested that aging sensitizes the ovaries to radiation damage. ${ }^{1}$

This suggested relationship between temporary ovarian failure and age of administration is further supported in another study by Raymond. ${ }^{3}$ Their study showed that patients with menstrual disturbances were significantly older. The authors emphasized that increasing age is positively correlated with the risk for autoimmunity which has been circumstantially associated with the appearance of ovarian failure.

The dose received by the group with menstrual changes was significantly higher. A higher dose may lead to increased ovarian exposure which could possibly explain the disturbance. This was seen in the study by Raymond, were subjects with ovarian failure received slightly higher doses and also had marginally higher calculated ovarian doses. However, none of the patients who received a repeat dose of RAI in our study had such disturbances after the second dose. This suggests that a higher exposure at one single point may have more effect than cumulative exposure.

Aside from the age and dose of RAI, other factors which could lead to menstrual disturbances should also be evaluated. Thyroid hormone deficiency should be a primary consideration since the menstrual changes in the majority of affected subjects occurred when they were in a state of induced hypothyroidism. Hypothyroidism is a known cause of reproductive dysfunction. ${ }^{4}$ In this condition, there is a disruption in gonadotropin secretion due to impaired conversion of estrogen. ${ }^{5}$ However, all subjects underwent thyroid hormone withdrawal prior to RAI and not all of them experienced changes. It is possible, that the degree and duration of hypothyroidism reached by the subject is responsible for the difference.

Other endocrine dysfunctions could also produce menstrual changes. These patients are subjected to both emotional and physical stresses which could lead to endocrine disruptions particularly of the hypothalamic pituitary-gonad axis. ${ }^{4}$ Stress is a known contributor to functional hypothalamic dysfunction, where there is inadequate gonadotropin secretion secondary to altered pulsatile GnRH secretion. Stress could also chronically activate the pituitary adrenocortical axis. This leads to elevated secretion of $\mathrm{CRH}$ and cortisol which may also contribute to functional hypothalamic dysfunction. 
Menopause is a reproductive event that may be affected by RAI. In this study, 4 women were menopausal at an average age of 44.4 years. The age of menopause was also previously reviewed by Ceccarelli ${ }^{6}$ and Souza. ${ }^{7}$ Compared to these studies, the current report's subjects received RAI earlier and went into menopause earlier as well. The interval between radiation treatment and menopause was similar in all studies at 10 years.

These 2 studies had control groups which reached menopause at a significantly later age compared to the RAI treated group. The authors suggest that incidental irradiation of the ovaries triggers follicular atresia or damage, and this hastens the natural decrease in ovarian function. They also suggested hypothalamic stress and thyroid autoimmunity as possible causes for the early decline.

However, not all studies have shown early menopausal onset. In a similar study done by Munoz, ${ }^{8}$ they also reviewed the menopausal age but used a different type of control compared to the abovementioned studies. For controls, they compared the subject's mean age of menopause to their mothers and sisters' age of menopause. They concluded that menopause did not occur earlier in patients than in their first degree relatives.

Another significant concern for patients undergoing radiation treatment is post treatment fertility. In this study, 5 out of 11 women who were actively attempting conception were able to get pregnant and give birth. These subjects were younger compared to their counterparts and received a higher radioactive dose. This is consistent with the observation that younger patient's ovarian function is more resilient and capable of receiving higher doses. ${ }^{1}$ Another possible explanation is that the other subjects who have not conceived post treatment were older, hence have decreased fertility.

Sioka ${ }^{2}$ also reviewed the pregnancy outcomes among their subjects. Out of 45 subjects, there were 6 reported pregnancies or $13.3 \%$, which is nearly the same as the current study. This report also had no incidents of congenital anomalies.

Garsi ${ }^{6}$ reported data on pregnancy outcomes among 2,673 pregnancies, before and after radioactive iodine. The only statistically significant finding was a doubling of miscarriage rates to $20 \%$ after RAI. However, after adjustment for age of pregnancy, this became insignificant. In our study, there was only 1 report of miscarriage and this occurred at the age of 40 . Other pregnancy outcomes that were also reviewed by Garsi included stillbirths, preterm births and congenital malformations and were not different before and after treatment.

\section{Conclusion}

This study showed that the prevalence of menstrual disturbances after high dose RAI treatment among thyroid cancer patients is $15.2 \%$. The affected group received a significantly higher activity compared to the unaffected group. None of the affected group received more than 1 dose. Five out of the 11 women trying to conceive were able to give birth, with 1 report of miscarriage and no reports of congenital anomalies. Four were in menopause at the time of the study. Their mean age of menopause was 44.4 years old.

It is recommended that a prospective study be done, with enrollment of subjects occurring immediately after ablative therapy. This is to bypass the limitations of the current study which includes recall bias. Thyroid uptake prior to treatment should also be reviewed to get a more accurate data on the actual dose received by the patient. Biochemical assessment (FSH, LH) should also be done to add an objective assessment of ovarian dysfunction. Assessment of the contribution of the other endocrine systems should also be done to determine their contribution. Thyroid function, specifically TSH, should also be taken at baseline and periodically afterwards to assess the possible effect of the thyroid status on ovarian function. Evaluation of the pituitary adrenal axis should also be considered.

\section{References}

1. Vini L, Hyer S, Al-Saadi A, Pratt B, Harmer C. Prognosis for fertility and ovarian function after treatment with radioiodine for thyroid cancer. Postgrad Med J 2002; 78:92-93

2. Sioka C, Kouraklis G, Zafirakis A, Manetou A, Dimakopoulos N. Menstrual cycle disorders after therapy with iodine-131. Fertil Steril. September 2006; 86(3):625-629

3. Raymond JP, Izembart M, Marliac V, Dagousset F, Merceron RE, Vulpillat M. Temporary ovarian failure in thyroid cancer patients after thyroid remnant ablation with radioactive iodine. J. Clin. Endocrinol. Metab. 1989; 69:186-190.

4. Kronenberg H. Williams Textbook of Endocrinology $11^{\text {th }}$ edtion. Saunders Elsevier, 2008

5. Gardner D. Greenspan's Basic and Clinical Endocrinology $8^{\text {th }}$ edition. McGraw-Hill Companies, 2007

6. Ceccarelli C, Bencivelli W, Morciano D, Pinchera A, Pacini F. 131 I therapy for differentiated thyroid cancer leads to an earlier onset of menopause: Results of a retrospective study. J. Clin. Endocrinol. Metab. 2001; 86:3512-3515

7. Souza R, Alvarenga F, Villas-Boas F, et al. Radioiodine therapy and age at menopause in patients with thyroid cancer. Clinical Endocrinology. 2006; 64:225-226.

8. García-Quirós M, Muñoz J, Hernández M, Torres C. Age of menopause in patients with differentiated thyroid cancer treated with radioiodine. Endocrinol Nutr. March 2010; 57(3):105-109.

9. Garsi J., Schlumberger M., Rubino C. et al. Therapeutic administration of ${ }^{131} \mathrm{I}$ for differentiated thyroid cancer: Radiation to ovaries and outcome of pregnancies. J Nucl Med. May 2008; 49(5):845-852. 